\title{
Una escuela para el odio: \\ los demonios familiares de la Historia de España
}

A School for Hatred: The Family Demons in the History of Spain

\author{
José Carlos Bermejo Barrera \\ Universidad de Santiago de Compostela \\ josecarlos.bermejo@usc.es \\ Para Sonia y Bruno.
}

\section{Resumen}

Las historias nacionales son relatos en torno a un protagonista, el pueblo, que permanece vivo a lo largo de los siglos. La historia no se puede escribir sin documentos ni hechos, pero los relatos históricos se estructuran mediante unos meta-relatos, que dan sentido y significado al proceso histórico global. A partir del siglo XV y hasta el siglo XX, las Historias de España se construyeron como relatos acerca de una identidad escindida. Ello se debió al omnipresente miedo a las personas con identidades ocultas: marranos, espías protestantes, traidores y quinta columnistas y luego masones o liberales, nacionalistas y comunistas. Todo ello creó un discurso interminable y generador de odio sobre la traición y los traidores ocultos.

\section{Palabras clave}

Historia de España, relato, odio, traición

\begin{abstract}
National histories are stories about a protagonist, the people, who remain alive throughout the centuries. History cannot be written without documents or facts, but historical accounts are structured through meta-stories, which make sense of and give meaning to the global historical process. From the fifteenth century and until the twentieth century, the History of Spain books were constructed as narratives about a split identity. This was due to the omnipresent fear of people with hidden identities: "marranos", protestant spies, traitors and fifth columnists and then freemasons or liberals, nationalists and communists. All this created an endless discourse generator of hatred about treason and hidden traitors.
\end{abstract}

\section{Key words}

Historia de España, narrative, hatred, treason. 
Una de las grandes contribuciones del judaísmo a la historia occidental ha sido la creación de la semana. Fue la religión judía la primera que construyó un ciclo fijo del tiempo de siete días de duración, que se mantendría de modo uniforme a lo largo de todos los meses del año. ${ }^{1}$ La sucesión de las semanas a lo largo del año hizo posible, a su vez, que los judíos creyesen que el tiempo social se abría y se cerraba periódicamente, y así lo conmemoraban con los rituales de la celebración del Shabbath.

Según el Talmud de Babilonia tenemos dos ángeles que simbolizan los buenos y malos deseos, y esos ángeles, llamados ministeriales, acompañan a cada persona en el camino de vuelta de la sinagoga los viernes por la noche. Si la casa está lista para el Shabbat con el encendido de las velas y la preparación de la mesa con vino y la comida adecuada, el ángel que representa los buenos deseos da su bendición: "que el próximo Shabbat sea igual". En ese caso el ángel que representa los malos deseos estará obligado a responder "amén". Sin embargo, si la casa no ha sido preparada, será entonces el ángel de los malos deseos el que dirá lo mismo y el que representa la buena inclinación no tendrá más remedio que responder "amén", iniciándose de este modo una funesta semana.

Estos dos ángeles del tiempo fueron consagrados en la historiografía por Walter Benjamin en su archiconocido texto sobre "El ángel de la Historia". No centraremos en él nuestra atención sino en un texto escrito por los cabalistas de la ciudad Palestina de Safed en el siglo XVII, que se canta como un ritual casi mágico para asegurar el inicio de la buena semana. Su texto transliterado en hebreo con fonética sefardita dice:

Shalom alejem malajé hasaret malajé Elyón, mimélej maljé hamelajim Hakadosh Baruj hu.

Boajem leshalom malajé hashalom malajé Elyón, mimelej maljé hamelajim Hakadosh Baruj Hu.

Barejuni leshalom malajé hashalom malajé Elyón, mimélej maljé hamelajim Hakadosh Baruj Hu.

Betsetejem leshalom malajé hashalom malajé Elyón, mimelej maljé hamelajim Hakados Baruj Hu.

Así recitarían este encantamiento nuestros judíos sefarditas desde el norte al sur de la Península, esperando que el tiempo que se acaba y el tiempo que comienza en la historia les trajese la paz. Pues como dice su letra:

Que la paz esté con vosotros, ángeles ministeriales, ángeles del Altísimo, el supremo Rey de Reyes, es santo, bendito es.

Que su venida sea en paz, ángeles de la paz, ángeles del Altísimo, el supremo Rey de Reyes, es santo, bendito es.

Bendecidme con paz, ángeles de la paz, ángeles del Altísimo, el supremo Rey de Reyes, es santo, bendito es.

Que su salida sea en paz, ángeles de la paz, ángeles del Altísimo, el supremo Rey de Reyes, es santo, bendito es.

El texto se cantaba al compás de unas melodías tradicionales, que fueron adaptadas por el rabino Israel Golfarb en 1918, y esa versión se hizo tan famosa que alguna gente cree que le fue revelada a Moisés en el monte Sinaí. ${ }^{2}$

${ }^{1}$ Ver E. Zerubabel, The Seven Day Circle. The History and Meaning of the Week (New York: The Free Press, 1985).

${ }_{2}^{2}$ Puede escucharse en la interpretación de Susana Allen, fácilmente localizable en Youtube. 
Es muy adecuado comenzar con este texto porque en él quizás el protagonista más importante en esta historia hispánica de la traición y el odio sea el judío, practicante primero, y luego el marrano, el criptojudío, aquel al que la Inquisición podía condenar a la hoguera por encender precisamente velas en su casa en la noche del viernes al sábado. Los judíos de España no siempre pudieron celebrar el comienzo en paz de la nueva semana, como tampoco la mayor parte de los pueblos de la historia pudieron celebrar así el cambio entre los diferentes períodos y épocas de la misma. Pero en este caso su sufrimiento fue quizás mayor, pues quedaron al albur de reyes y fanáticos cuando a partir del Baja Edad Media comenzaron a estallar los diferentes pogromos, y vieron culminar todo este proceso de persecución y odio inducido con su expulsión de su patria, Sefarad, por parte de los "Reyes Católicos".

Es cierto que los judíos fueron expulsados siglos antes de Inglaterra que de España, pero lo específico de España, tal y como señala B. Netanyahu, ${ }^{3}$ es que se utilizó todo el poder del aparato inquisitorial para descubrir y castigar al marrano, al judío oculto, formalmente cristiano pero que no podía borrar de su sangre su esencia judía rastreable en sus apellidos investigados en los estatutos de limpieza de sangre. No se trataba de acabar con una religión prácticamente extinguida ni de perseguir a un enemigo real, sino de depurar en el interior de una sociedad a un enemigo imaginario que no era más que una proyección negativa de los miedos y los vicios de la sociedad cristiana. En realidad toda la sociedad española quedó marcada para siempre por lo que podríamos llamar, siguiendo a Y Yovel, "el síndrome del marrano". "De acuerdo con él nadie puede considerarse a sí mismo como puro. Todo el mundo tiene algo que ocultar y todo el mundo debe mentir y fingir. La identidad escindida española sería pues la identidad de una sociedad de hipócritas. Un chiste recogido por Yovel lo expresa muy bien. En una ciudad del norte de Portugal llega el barón Rotschild a ver una iglesia. El sacristán le dice que en ella hay una virgen que llora al ver a un judío, porque, claro está, le habría matado a su hijo. Al salir le dice el barón al sacristán cicerone: "eso no es verdad, yo soy judío y la virgen no ha llorado". A lo que responde el sacristán: "¡cállese hombre no ve que me va a descubrir a mí también!”.

Nadie es puro y por eso la mejor manera de demostrar que lo es es descubrir o llegar a descubrir que el judío oculto, el traidor, siempre es el otro, frente al que me uniré con el resto de esa comunidad a la que cínicamente confieso pertenecer. El judío es el portador de secretos inconfesables en sus costumbres, sus creencias y su culto, por eso se le considera el maestro de la conspiración y el conocedor y controlador de los grandes secretos en los campos de la magia, el conocimiento científico y el comercio y las relaciones económicas. Los judíos, por su conexiones internacionales, pueden disponer del conocimiento geográfico y estratégico de toda una región, por ejemplo el mundo mediterráneo en el caso de Nicolas Fabri de Peiresc (1580-1637), quien desde Marsella

\footnotetext{
${ }^{3}$ B. Netanyahu, The origins of the Inquisition in Fifteenth Century Spain (New York: Random House, 1995).

${ }^{4}$ Y. Yovel, The Other within. The marranos. Split Idendity and Emerging Modernity (Princeton University Press, 2009). Anteriormente había tratado el tema de los marranos Cecil Roth, Los judios secretos. Historia de los marranos (Madrid: Altalena, 1976), así como Julio Caro Baroja en su obra fundamental, Los judíos en la España moderna y contemporánea, tomos I-III (Madrid: Arion, 1961).
} 
consiguió reconstruir toda una trama de relaciones personales e informaciones comerciales y de todo tipo que abarcaban todo el Mare Nostrum. ${ }^{5}$

Para ellos no solo disponía de la infraestructura que le proporcionaban las familias de los sefardíes salidos de España tras la expulsión, y que se extendían hasta Grecia y el resto del mundo otomano, ${ }^{6}$ sino de una amplia red de relaciones en el seno del imperio Otomano. Esas redes de relaciones que se podían extender además hasta el norte de Europa, Escandinavia, Rusia y Polonia, fueron la base para que se construyese la idea de que los judíos podían ser conspiradores ocultos organizados a nivel internacional con el fin de enriquecerse personalmente, favorecer a un rey o a un reino o causar de la misma manera la ruina de otro. ${ }^{7}$ Una idea que en cierto modo puede considerarse como una continuación de la imagen del judío como envenenador de las fuentes y causante de la peste en la Edad Media. ${ }^{8}$ En ella la corrupción física causada por la enfermedad a veces se asoció a los excesos sexuales atribuidos a los leprosos y a los judíos simultáneamente, quienes contagiarían la enfermedad a través del contacto sexual. Leprosos y judíos fueron dos especies de excluidos tratados a veces de la misma forma, pero mientras la condición de leproso fue concebida como una enfermedad o una maldición individual, la del judío fue una condición colectiva, lo que los hacía más peligrosos como portadores de gérmenes, de la misma manera que fueron retratados en la propaganda nazi. ${ }^{9}$

Solo con la súbita aparición de la sífilis, una enfermedad cuyos síntomas dermatológicos pueden hacerla a veces similar a la lepra por ser llamativos y desagradables, quedó claro que el contagio por vía sexual ya no podía ser patrimonio de los judíos o los leprosos. Cada país designó a la sífilis con el nombre del país vecino, porque encarnaba al otro. Los ingleses y españoles le llamaron el "mal francés", los portugueses el "mal castellano", los japoneses el "mal portugués", los rusos el "mal polaco", y así sucesivamente. ${ }^{10}$

El judío fue durante siglos objeto privilegiado del odio de la Europa cristiana por ser un emboscado, un traidor que vive en nuestra propia casa. ${ }^{11} \mathrm{Y}$ así lo veremos desde

\footnotetext{
${ }^{5}$ Estudiado por Peter N. Miller, Peiresc's Mediterranean World (Harvard University Press, 2015).

${ }^{6}$ Sobre ellos y sus sistemas de relación ver Esther Benbassa y Aron Rodrigue, Historia de los judios defardíes. De Toledo a Salónica (Madrid: Abada Editores, 2004), así como el libro coordinado por Henry Méchoulan, Historia de una diáspora (1492- 1992) (Madrid: Trotta, 1993 [Paris, 1992]). También puede ser muy útil para su estudio el libro de Jeffrey S. Malka, Sephardic Genealogy. Discovering your Sephardic Ancestors and their World (Bergenfield, New Jersey: Avotaynu Inc., 2009).

${ }^{7}$ Como ha señalado Daniel Jütte, The Age of Secrecy. Jews, Christians and the Economy of Secrets, 14001800 (New Haven and London: Yale University Press, 2015 [Göttingen, 2012]).

${ }^{8}$ Sobre este tema es esencial el libro de Olwe J. Benedictow, La Peste negra (1346- 1353). La historia completa (Madrid: Akal, 2011). Pueden verse datos interesantes en este sentido también en el libro de A. Lloyd Moote y Dorothy C. Moote, The Great Plague. The Story of London's most deadley year (Baltimore: Johns Hopkins University Press, 2004), y en el libro, no por antiguo carente de interés, de Francis Aidan Gasquet, The Great Pestilence (A.D. 1348-9). The Black Dead (London: Simpkin Marshall, Hamilton Kent and Co, 1893).

${ }^{9}$ Sobre la lepra y la condición del leproso ver Françoise Bériac, Histoire des Lépreux au Moyen Âge. Une societé d'exclus (Paris: Imago, 1988) y Anthony Weymouyh, Through the Leper-Squint. A study of Leprosy from Pre-Christian Times to the Present Day (Plymouth: Selwyn and Blount, 1938).

${ }^{10}$ Ver Claude Quétel, History of Syphilis (Oxford: Polity Press, 1990 [Paris, 1986]).

${ }^{11}$ De hecho es significativo que Leon Poliakov, uno de los primeros grandes expertos en el Holocausto, titulase su libro sobre el tema Breviare de la haine. Le III Reich et les juifs (Paris: Calmann-Levy, 1951).
} 
el comienzo de la Edad Media colaborando con el musulmán, el gran enemigo externo, para entregarle el reino visigodo de Hispania. Pasará luego a ser el colaborador de todos los enemigos posibles, los ingleses, los franceses, los turcos; y a ser identificado con ese otro enemigo interno que posteriormente serán los ilustrados y los masones, y a representar luego el poder internacional del capital y las grandes conjuraciones mundiales, como la de los Protocolos de los Sabios de Sión, una falsificación de la policía política zarista. Todo ello desemboca en el antisemitismo racista del nazismo, que será uno de los grandes divulgadores de estos falsos protocolos.

En España se da la paradoja de que el antijudaísmo secular fue asumido por dos de los nacionalismos periféricos, el gallego y el vasco, a pesar de que históricamente el número de judíos presentes en esos territorios fue muy pequeño. En el caso gallego, algunos intelectuales nacionalistas como Vicente Risco escribieron textos claramente antisemitas, y el antisemitismo de este autor aún forma parte del nacionalismo gallego de izquierdas. En plena II Guerra Mundial, a pesar de las dificultades económicas y con el aval de la censura franquista, Risco publica una Historia de los Judios, en la que sostiene que todo lo peor (pero a la vez lo más brillante) de la historia proviene del pueblo judío. ${ }^{12}$ A pesar de su carácter muchas veces nocivo, sostiene que sin embargo que no debería ser exterminado, sino solo controlado, para que no se cumpla la profecía de san Agustín según la cual cuando el pueblo judío se extinga llegará el fin del mundo. Un libro en el que consideraba que los nazis deberían tomar alguna medida contra el judaísmo, aunque no podía conocer, ni creo que hubiese aprobado, la "solución final", pues estaría en contra de su pensamiento católico integrista.

En el caso del nacionalismo vasco, la filiación entre el antijudaísmo católico y la obsesión por la limpieza de sangre inquisitorial es evidente en el pensamiento de Sabino Arana, un católico ultra-reaccionario en el campo social e intelectual, que estableció como uno de los componentes del partido que fundó su carácter confesional. Es curioso que su partido, el PNV, haya solicitado por tres veces la santificación de su fundador, y que todos los mítines de la etapa inicial el partido se celebraban en el atrio de una iglesia al salir de misa. ${ }^{13}$ Para los nacionalismos gallego y vasco en algunas de sus vertientes, el judío es a la vez el enemigo interno, como ocurre en la historia de España, y el enemigo externo, porque se lo asocia con los poderes centrales de los distintos momentos históricos. El judío será en la historia de España a la vez el arquetipo de la traición y de la impureza racial, y el objeto preferente del odio de eclesiásticos, políticos y de los grandes autores que han narrado la Historia de España, excepto destacables excepciones como la de Amador de los Ríos ${ }^{14}$ o Francisco Fernández y González. ${ }^{15}$

Sobre las formas de concebir a los judíos ver David Nirenberg, Antijudaism. The History of a Way of Thinking (London: Head of Zeus, 2013).

12 Vicente Risco, Historia de los judios desde la destrucción del Templo (Barcelona: Ediciones Gloria, 1942).

13 José Luis de la Granja Sainz, Ángel o demonio: Sabino Arana. El patriarca del nacionalismo vasco (Madrid: Tecnos, 2015).

${ }^{14}$ Amador de los Ríos, Historia social, política y religiosa de los judíos de España y Portugal (Madrid: Aguilar, 1960 [ed. or. 1875]).

${ }^{15}$ Francisco Fernández y González, Instituciones jurídicas del pueblo de Israel en los diferentes estados de la Península Ibérica desde su dispersión en tiempo del Emperador Adriano hasta los principios del siglo XVI (Madrid: Imprenta de la revista de Legislación, 1881). 
De hecho, si queremos estudiar la historia de la edad de oro del judaísmo sefardí tendremos que utilizar las grandes síntesis de historiadores judíos contemporáneos, como es el caso de Yitzhak Baer, ${ }^{16}$ para la Edad Media en general, de Yom Tov Assis, ${ }^{17}$ para la Corona de Aragón, y de Eliyahu Asthor, para la España islámica. ${ }^{18}$

Los judíos de España , como los demás judíos desde el siglo I de nuestra era hasta el siglo XIX, no han escrito libros de historia, porque, como ha señalado $\mathrm{Y}$. $\mathrm{H}$. Yerushalmi, ${ }^{19}$ para el pueblo judío lo esencial es la memoria viva, el recuerdo de los lugares, las familias y los hechos de un pasado que se mantiene vivo mediante las narraciones, los poemas, las canciones y las celebraciones rituales que conmemoran los grandes acontecimientos del pasado, real o imaginario, como la huida de Egipto, la cautividad de Babilonia o la destrucción del templo de Jerusalén.

Por el contrario, desde la Edad Media los cronistas e historiadores sí que escribieron numerosas historias de España y de sus reinos en las que los judíos aparecen como traidores y emboscados internos y una larga serie de personajes y colectividades han venido siendo protagonistas de un tema obsesivo en esta historiografía: la traición y los traidores. ${ }^{20}$

En las historias de España, a partir del momento en el que se asiente la crítica histórica, se dejarán de lado las viejas leyendas y solo se incluirán los hechos realmente ocurridos en el pasado, como la toma de Numancia, la muerte de Viriato, la "pérdida de España", la vida del Cid, y otros tantos temas. Lo que ocurre es que, aunque todos estos hechos hayan sido ciertos, la totalidad del relato no lo es de la misma manera. Y es que ningún relato ni ninguna totalidad puede ser verdad o mentira, sino solo narraciones convincentes o no, para unos o para todos.

Un hecho es como un ladrillo o el sillar de un muro. Sin ladrillos no hay paredes y sin sillares no hay muros, pero con sillares también se pueden hacer bóvedas, cúpulas, arcos, puentes, fortificaciones y castillos. Cuando un historiador escribe narra hechos que se refieren a acontecimientos que fueron reales, pero esos hechos adquieren un significado diferente según el tipo de relato que escojamos. La conquista de la Península por el Islam es un hecho positivo desde la perspectiva musulmana, pero no lo es desde la cristiana, y lo mismo ocurre con el "descubrimiento de América", la "Guerra de la Independencia" o las guerras carlistas y la Guerra Civil.

\footnotetext{
16 Yitzhak Baer, Historia de los judíos en la España cristiana (Barcelona: Riopiedras, 1982 [Tel Aviv, 1959]).

17 Yom Tov Assis, The Golden Age of Aragonese Jewry. Community and Society in the Crown of Aragon, 1213-1327 (London: The Littman Library of Jewish Civilization, 1997).

${ }^{18}$ Eliyahu Asthor, The Jews of Moslem Spain, I-III (Philadelphia: Jewish Publication Society of America, 1973, 1979 y 1984). Por supuesto historiadores españoles como Luis Suárez Fernández o Julio Valdeón Baruque y tantos otros han llevado a cabo estudios sobre los judíos en la Edad Media y sobre su expulsión, pero siempre desde la perspectiva española y de modo puntual.

${ }^{19}$ Y. H. Yerushalmi, Zakhor. Histoire juive et mémoire juive (Paris: Gallimard, 1982).

${ }^{20}$ Sobre este tema ver el exhaustivo estudio de Bruno Padín Portela, La traición en la Historia de España (Madrid: Akal, 2019), en el que pueden verse todos las casos que se citarán a continuación y sus respectivas fuentes.
} 
En la historia de España hay traiciones reales, y traidores reales a veces e imaginarios otras. La traición posee importantes aspectos jurídicos y políticos, pero puede además convertirse en un leit motiv narrativo que flota como una maldición a lo largo de los siglos, como puede verse en el estudio de B. Padín. Para comprender su función política y narrativa no se trata de hacer un exhaustivo catálogo de traidores y traiciones sino de estudiar una construcción narrativa global, en la que la sucesión de traiciones durante más de veinte siglos en los libros de historia adquiere un significado propio y suscita dos emociones muy concretas, básicamente el rechazo y el odio.

La sucesión de traiciones y traidores estudiados por B. Padín es como las notas de una larga sinfonía, que se van desplegando desde el compás inicial al compás final, manteniendo siempre el mismo tema a lo largo de sus diferentes movimientos. Y ese tono es el del odio, un odio que pide venganza por la traición, que nos pide que nos mantengamos siempre alerta y con los ojos abiertos ante el traidor que eternamente nos acecha y vigila nuestra debilidad. El estudio y la lectura de los libros de historia será la fórmula mágica contra ese peligro, pero no una fórmula mágica como la del Shalom alejem de nuestros cabalistas que solo desean finales y comienzos con paz, sino todo lo contrario, una fórmula y un grito de alerta y muchas veces una llamada a la represión o a la guerra.

El odio que suscita la traición es una parte esencial de la naturaleza humana, porque el odio es lo contrario del amor. Por eso se puede odiar tanto lo que y a quien se ha amado y a quien ha roto el compromiso de fidelidad, sea del tipo que sea. El odio está directamente unido a la violencia, tanto la que se sufre como la que se puede infligir a los demás. Y la violencia, el odio y la ira son parte esencial de la vida animal y humana. ${ }^{21}$ Los cerebros, animales o humanos, están dotados de mecanismos neurológicos básicos que activan las respuestas de alerta y de huida o de agresión. Sin ellos ningún animal podría sobrevivir, pero nuestro odio es algo muy diferente, porque no se trata del odio de una persona a otra porque le haya infligido una ofensa, sea del tipo que sea, sino de un odio compartido, organizado e inducido con el fin de movilizar a grandes o pequeños grupos.

Una ofensa pide una venganza o una compensación en bienes o servicios y la historia de derecho penal puede interpretarse, tal y como ha hecho Jr. Julius Goebel, como el paso de la idea de injuria u ofensa, a la idea de delito. ${ }^{22}$ La injuria se le inflige a una persona y genera odio y deseo de venganza; el delito daña a una persona, pero es un hecho social compartido que exige un castigo racional de acuerdo con un procedimiento establecido y regulado por una ley. Y con ese castigo se pone fin al delito, mientras que la injuria y la ofensa suelen perdurar durante muchas generaciones, y por eso la historia puede ser esencial para narrarlas, ya sea una historia familiar o nacional.

No hay injurias colectivas que pidan venganza más que en el caso de los libros de historia, o en las bocas de los políticos y agitadores que claman pidiendo una guerra y

${ }^{21}$ Ver E. Salgado, Radiografía del odio (Madrid: Guadarrama, 1969) y C. Castilla del Pino (ed.), El odio (Barcelona: Tusquets, 2002), así como el tratamiento más sistemático de A.T. Beck, Prisioneros del odio. Las bases de la ira, la hostilidad y la violencia (Barcelona: Paidós, 2003 [New York,1999]).

22 Jr. Julius Goebel, Felony and Misdemeanor. A Study in the History of English Criminal Procedure (London: The Commonwealth Fund, 1937). 
excitando el odio. Pero el odio colectivo se suele centrar en un enemigo externo, ya sea otro reino, otro pueblo, otra religión, otras razas, o los pueblos de otros continentes lejanos o cercanos. Así ha narrado la crónica de ese odio en el siglo XIX Peter Gay. ${ }^{23}$ El objeto del odio colectivo, organizado e inducido, y consagrado por el relato histórico, suele ser el eterno enemigo exterior, como el francés frente al alemán, o el español frente al inglés, el cristiano frente al musulmán, o el judío contra el musulmán, más recientemente.

Sin embargo en los relatos de la historia de España nos vamos a encontrar con algo muy peculiar, y es que la insistencia en destacar el papel narrativo de la traición y los traidores en ella no solo es un artificio literario, que jamás podría hallar una plena verosimilitud en los grandes tratados oficiales de la historia de un reino, una nación o un pueblo, sino que es algo mucho más profundo, que podríamos llamar la maldición de Caín. La maldición de un país que siempre dudó de su identidad y que no duda en buscar traidores a los que achacar su fracaso en cada época.

La España prerromana carece de unidad porque no hay un pueblo único que le sirva de sustrato, sino muchos, o por los menos dos: íberos y celtas, semitas e indoeuropeos en la versión de Vicente Risco, que se fundirían en un único pueblo, los celtíberos, que proporcionarían el sustrato étnico de la historia de España, o que quedarían eternamente divididos, como cuando Murguía reivindique el componente celta como exclusivo de Galicia, o el nacionalismo vasco reivindique sus derechos como el pueblo primigenio y más antiguo de Europa, siguiendo las huellas de W. von Humboldt, estudioso alemán de la lengua vasca a comienzos del siglo XIX. ${ }^{24}$

Cada nacionalismo hispánico reivindicará su base étnica y aunque los hispanos actúen supuestamente unidos frente a Roma en la historia secular de la conquista romana de Hispania, la traición estará presente en primer plano en la muerte de Viriato y la maldición de las guerras civiles de la propia Roma republicana, que alcanzará su apogeo con la figura de Sertorio. De la misma manera Roma tampoco será capaz de garantizar esa unidad, al mantener siempre la existencia en la Península de diferentes provincias, y por eso habrá que esperar a los visigodos para que esa idea de unidad se consolide gracias a la imposición por parte del poder real y los poderosos instrumentos que fueron los Concilios de Toledo, de la religión católica, unida desde entonces a la supuesta esencia nacional española. Esa falta de unidad fue considerada como el problema capital de la historia de España por parte de José Ortega y Gasset en su España Invertebrada. ${ }^{25}$

La unión de la religión y el poder real en el mundo visigodo continuará presente en la Edad Media con la pervivencia de la idea de Hispania en las monarquías asturiana,

\footnotetext{
${ }^{23}$ Peter Gay, The Cultivation of Hatred. The Bourgeois Experience. Victoria to Freud (London: Norton Company, 1993).

${ }^{24}$ Sobre este tema es esencial el libro de Fernando Wulff Alonso, Las esencia patrias. Historiografía e Historia Antigua en la construcción de la identidad española (siglos XVI- XX) (Barcelona: Crítica, 2003). Y para la historiografía gallega, J.C. Bermejo Barrera, ¿Para qué serve a Historia de Galicia? (Santiago de Compostela: Lóstrego, 2007).

${ }^{25}$ José Ortega y Gasset, España Invertebrada. Bosquejo de algunos planteamientos históricos (Madrid: Espasa Calpe, 1922). Sobre este tema ver John T. Graham, A pragmatist Philosophy of Life in Ortega y Gasset, I. Theory of History in Ortega y Gasset. II. The Dawn of Historical Reason, y III. The Social thought of Ortega y Gasset. A Systematic Synthesis in Postmodernism and Interdisciplinarity (Columbia: University of Missouri Press, 1994, 1997 y 2001).
} 
leonesa y castellana, pero la ocupación musulmana la consolidará aún más, al tener lugar un enfrentamiento entre diferentes reinos que es a la vez un enfrentamiento entre dos religiones y dos mundos en el que los judíos están integrados en cada una de las dos partes, por lo que cada una de las dos les podrá achacar a veces estar colaborando con la otra parte, ser traidores a veces en una dirección doble, cuando en realidad solo eran fieles a su propia religión e intentaban sobrevivir en cada ciudad y cada reino.

Pero es que además en la España cristiana convivirán diferentes reinos: León y Castilla, Navarra, Aragón, con distintas configuraciones según las épocas, no existiendo la idea de una monarquía unitaria hasta la llegada de los Borbones en el siglo XVIII, en el que los intentos de reforma y racionalización de la administración y mejora de la economía se encontrarán con la resistencia de poderes locales, fueros y privilegios, pasando así en cierto modo a ser la propia razón un elemento ajeno a la historia de España. ${ }^{26}$ La razón se asociará a lo ajeno y a lo externo, a la nueva monarquía o al ejército invasor de Napoleón, y sus nuevos traidores emboscados serán los masones y los traidores afrancesados. $^{27}$

En la historiografía de España da la impresión de que el cultivo y la crianza del odio se encauzaron tanto hacia el enemigo exterior como contra los supuestos enemigos internos. Siglos de guerras entre reinos hispánicos medievales, levantamientos de catalanes y repetidas guerras carlistas parecieron querer desembocar casi naturalmente en nuestra guerra civil, en la crisis de la idea de España y en la génesis de unos nacionalismos que pasaron a asumir el rol de traidores, una vez que la consolidación del sistema parlamentario, haya sido mejor o peor, desterró la idea de que el rival político no puede ser un traidor, ya que es consustancial a la democracia parlamentaria la idea de oposición. ${ }^{28}$

No obstante, una vez instaurada la democracia parlamentaria en el siglo XIX, en España, el país que ya había expulsado a los judíos cuatro siglos antes, el antisemitismo siguió en vigor y sigue estándolo en el siglo XXI. El antisemitismo religioso tradicional se renovó con el nuevo antisemitismo racial en el siglo XX y se reforzó con el antisemitismo nazi y con el antisemitismo supuestamente izquierdista que siempre identifica de un modo simplista judaísmo y capitalismo, tal como ha analizado Jacques Attali. ${ }^{29}$ En los estertores del franquismo, cuando Franco pronunció su último discurso en la Plaza de Oriente en el año 1975, el viejo aliado de A. Hitler volvió a hablar de la

\footnotetext{
${ }^{26}$ Como ha destacado Luis Rodríguez Arana, El desarrollo de la Razón en la cultura española (Madrid: Aguilar, 1962). Y sobre todo Pedro Cerezo Galán, El mal del siglo. El conflicto entre Ilustración y Romanticismo en la crisis finisecular del siglo XIX (Biblioteca Nueva: Universidad de Granada, 2003).

${ }^{27}$ Como ha señalado Derek Flitter, Spanish Romanticism and the Uses of History. Ideology and the Historical Imagination (London: Maney Publishing, 2006). Y Richard L. Kagan, Los cronistas y la Corona. La política de la Historia en España en las Edades Moderna y Contemporánea (Madrid: Marcial Pons, 2009).

${ }^{28}$ Este tema ha sido estudiado por José Álvarez Junco, Mater Dolorosa. La idea de España en el siglo XIX (Madrid: Taurus, 2001), y por Carolyn P. Boyd, Historia Patria. Política, historia e identidad nacional en España: 1875- 1975 (Barcelona: Pomares Corredor, 2000 [Princeton, 1997]).

29 Jacques Attali, Los judios, el mundo y el dinero. Historia económica del pueblo judio (México: FCE, 2005 [Paris, 2002]).
} 
“conjuración judeo-masónica en lo político y marxista en lo social” ante un público que animaba al dictador en su decadencia física e intelectual final. ${ }^{30}$

En una democracia parlamentaria consolidada debe haber un gobierno, pero también quien se le oponga, y la traición solo debería ser un delito capital en caso de guerra contra el enemigo externo. Pero ¿qué ocurre si diferentes naciones se proclaman a sí mismas como unidades cerradas, mónadas perfectas incompatibles entre sí? Pues que entonces la idea del traidor y la traición renacen en toda su plenitud: vascos, gallegos y catalanes, por lo menos, son traidores a España, y a su vez en el seno de cada de esas naciones vuelve a haber enemigos internos: españoles agazapados que no quieren reconocer su verdadero ser y desean entregar a quienes sí lo hacen en manos de ese enemigo exterior y eterno que se enfrenta en los relatos contra los poderes centrales desde los comienzos de la historia hasta tiempo presente, siempre de la misma manera ejemplar.

Como las historiografías gallega, catalana y vasca se han construido por mímesis con la historia de España, sus arquetipos narrativos son idénticos. Los indígenas galaicos que luchan contra Roma son los mismos que los suevos que se enfrentan a los visigodos $\mathrm{y}$ que los nobles y los efímeros reyes gallegos que luchan contra los leoneses y castellanos. Y es que da la impresión de que los gallegos siempre se han enfrentado al centro desde su periferia, sea ese centro Roma, Toledo, León, Valladolid o Madrid.

Lo mismo ocurrirá en las historias de los vascos y catalanes. La traición sigue viva, el odio alerta y, al contrario que los judíos de España en su Shabatt, ya nadie parece querer que en la historia las épocas entren y salgan en paz, como pedían en su Shalom alején. Y no lo quieren, o parecen no quererlo, por la nostalgia de lo que Jon Juaristi ha llamado El bosque originario, ${ }^{31}$ porque quieren mantener viva la nostalgia del tiempo y el pueblo primigenios, puros y nunca contaminados, que nada deben ocultar en sus corazones de cristal. Todo vale para extirpar cualquier mancha o peligro oculto en ellos, para descubrir, apartar, y si es necesario liquidar a ese enemigo oculto al acecho, a ese marrano, que nunca parece poder ser extirpado del todo del alma de los pueblos hispánicos.

En la tradición romana y en las religiones del mundo antiguo existía la idea de que el nacimiento de un niño podría simbolizar la llegada de una nueva época de paz. Virgilio así lo describió en su IV Égloga, en la que el nacimiento de un niño, que los cristianos identificaron posteriormente y de modo interesado con Cristo -haciendo cristiano al poeta latino- supondría el fin del odio, las guerras civiles y la llegada de la paz que traerá a la tierra la vuelta de la Edad de Oro: redeant Saturnia regna. ${ }^{32}$ Tal y como se supone que lo habría logrado el emperador Augusto, al poner fin a las guerras civiles y ordenar el cierre de las puertas de templo de Marte.

Para los romanos el nacimiento de un niño marca el comienzo de una nueva época de paz en la historia política del mundo. Para los cristianos ese nacimiento será un acontecimiento esencial en la historia de toda la humanidad y de todo el universo, tal y

\footnotetext{
${ }^{30}$ Sobre el antisemitismo español en los siglos XIX y XX ver Gonzalo Álvarez Chillida, El Antisemitismo en España. La imagen del judío (1812-2002) (Madrid: Marcial Pons, 2002).

${ }^{31}$ Jon Juaristi, El bosque originario. Genealogías míticas de los pueblos de Europa (Madrid: Taurus, 2000).

${ }^{32}$ El tema literario del nacimiento del niño fue estudiado por E. Norden, Die Geburt des Kindes. Geschichte einer religiösen Idee (Stuttgart: Studien der Bibliotek Warburg, III, Teubner, 1930).
} 
como se celebra en la Navidad. De acuerdo con ese cambio tendría que llegar el reino de la justicia, la paz y la fidelidad, que es todo lo contrario de esa traición que los propios cristianos atribuyeron a los judíos, al no reconocer al hijo de su verdadero Dios y proclamarse como el Verus Israel, expropiándole al pueblo judío su libro sagrado y parte de su historia. ${ }^{33}$

Veíamos al comienzo cómo en el Shalom alejém el judaísmo marcaba el tránsito entre la unidad fundamental del tiempo que es la semana, intentando que el final de una época y el comienzo de otra siempre estuviesen soldadas por la paz. Los judíos de España mantuvieron este ritual, que aún sobrevive en la actualidad. Lo hicieron en sus aljamas y en sus casas, en las que vivieron durante siglos conviviendo unas veces bien y muchas mal con las comunidades religiosas que desempeñaban el poder político: cristianos y musulmanes. Los judíos siempre vivieron como una comunidad en el seno de otra comunidad, como una ciudad dentro de una ciudad. A ellos se les atribuyeron unas traiciones más imaginarias que reales durante las edades media y moderna. Esas traiciones han sido además creadas, criadas y acunadas por los autores de las historias de España y algunos historiadores de los diferentes nacionalismos periféricos, que da la impresión que han pensado que la historia, su escritura y su enseñanza han de ser sobre todo una escuela para el odio. Para un odio aprendido casi imposible de desaprender.

\section{Bibliografía}

A. Lloyd Moote y Dorothy C. Moote, The Great Plague. The Story of London's most deadley year (Baltimore: Johns Hopkins University Press, 2004)

A.T. Beck, Prisioneros del odio. Las bases de la ira, la hostilidad y la violencia (Barcelona: Paidós, 2003 [New York,1999])

Amador de los Ríos, Historia social, política y religiosa de los judíos de España y Portugal (Madrid: Aguilar, 1960 [ed. or. 1875])

Anthony Weymouyh, Through the Leper-Squint. A study of Leprosy from Pre-Christian Times to the Present Day (Plymouth: Selwyn and Blount, 1938)

B. Netanyahu, The origins of the Inquisition in Fifteenth Century Spain (New York: Random House, 1995)

Bruno Padín Portela, La traición en la Historia de España (Madrid: Akal, 2019)

C. Castilla del Pino (ed.), El odio (Barcelona: Tusquets, 2002)

${ }^{33}$ Ver Marcel Simon, Verus Israel. A Study of the Relations between Christians and Jews in the Roman Empire (A.D. 135-425) (New York: Littman Library of Jewish Civilization, 1995). 
Carolyn P. Boyd, Historia Patria. Política, historia e identidad nacional en España: 1875- 1975 (Barcelona: Pomares Corredor, 2000 [Princeton, 1997])

Cecil Roth, Los judíos secretos. Historia de los marranos (Madrid: Altalena, 1976)

Claude Quétel, History of Syphilis (Oxford: Polity Press, 1990 [Paris, 1986])

Daniel Jütte, The Age of Secrecy. Jews, Christians and the Economy of Secrets, 14001800 (New Haven and London: Yale University Press, 2015 [Göttingen, 2012])

David Nirenberg, Antijudaism. The History of a Way of Thinking (London: Head of Zeus, 2013)

Derek Flitter, Spanish Romanticism and the Uses of History. Ideology and the Historical Imagination (London: Maney Publishing, 2006)

E. Norden, Die Geburt des Kindes. Geschichte einer religiösen Idee (Stuttgart: Studien der Bibliotek Warburg, III, Teubner, 1930)

E. Salgado, Radiografía del odio (Madrid: Guadarrama, 1969)

E. Zerubabel, The Seven Day Circle. The History and Meaning of the Week (New York: The Free Press, 1985)

Eliyahu Asthor, The Jews of Moslem Spain, I-III (Philadelphia: Jewish Publication Society of America, 1973, 1979 y 1984)

Esther Benbassa y Aron Rodrigue, Historia de los judios defardíes. De Toledo a Salónica (Madrid: Abada Editores, 2004)

Fernando Wulff Alonso, Las esencia patrias. Historiografía e Historia Antigua en la construcción de la identidad española (siglos XVI- XX) (Barcelona: Crítica, 2003)

Francis Aidan Gasquet, The Great Pestilence (A.D. 1348-9). The Black Dead (London: Simpkin Marshall, Hamilton Kent and Co, 1893)

Francisco Fernández y González, Instituciones jurídicas del pueblo de Israel en los diferentes estados de la Península Ibérica desde su dispersión en tiempo del Emperador Adriano hasta los principios del siglo XVI (Madrid: Imprenta de la revista de Legislación, 1881)

Françoise Bériac, Histoire des Lépreux au Moyen Âge. Une societé d'exclus (Paris: Imago, 1988)

Gonzalo Álvarez Chillida, El Antisemitismo en España. La imagen del judío (1812-2002) (Madrid: Marcial Pons, 2002) 
Henry Méchoulan, Historia de una diáspora (1492-1992) (Madrid: Trotta, 1993 [Paris, 1992])

J.C. Bermejo Barrera, ¿Para qué serve a Historia de Galicia? (Santiago de Compostela: Lóstrego, 2007)

Jacques Attali, Los judios, el mundo y el dinero. Historia económica del pueblo judío (México: FCE, 2005 [Paris, 2002])

Jeffrey S. Malka, Sephardic Genealogy. Discovering your Sephardic Ancestors and their World (Bergenfield, New Jersey: Avotaynu Inc., 2009)

John T. Graham, A pragmatist Philosophy of Life in Ortega y Gasset, I. Theory of History in Ortega y Gasset. II. The Dawn of Historical Reason, y III. The Social thought of Ortega y Gasset. A Systematic Synthesis in Postmodernism and Interdisciplinarity (Columbia: University of Missouri Press, 1994, 1997 y 2001)

Jon Juaristi, El bosque originario. Genealogías míticas de los pueblos de Europa (Madrid: Taurus, 2000)

José Álvarez Junco, Mater Dolorosa. La idea de España en el siglo XIX (Madrid: Taurus, 2001)

José Luis de la Granja Sainz, Ángel o demonio: Sabino Arana. El patriarca del nacionalismo vasco (Madrid: Tecnos, 2015)

José Ortega y Gasset, España Invertebrada. Bosquejo de algunos planteamientos históricos (Madrid: Espasa Calpe, 1922)

Jr. Julius Goebel, Felony and Misdemeanor. A Study in the History of English Criminal Procedure (London: The Commonwealth Fund, 1937)

Julio Caro Baroja, Los judios en la España moderna y contemporánea, tomos I-III (Madrid: Arion, 1961)

Leon Poliakov, Breviare de la haine. Le III Reich et les juifs (Paris: Calmann-Levy, 1951)

Luis Rodríguez Arana, El desarrollo de la Razón en la cultura española (Madrid: Aguilar, 1962)

Marcel Simon, Verus Israel. A Study of the Relations between Christians and Jews in the Roman Empire (A.D. 135-425) (New York: Littman Library of Jewish Civilization, 1995) Olwe J. Benedictow, La Peste negra (1346-1353). La historia completa (Madrid: Akal, 2011)

Pedro Cerezo Galán, El mal del siglo. El conflicto entre Ilustración y Romanticismo en la crisis finisecular del siglo XIX (Biblioteca Nueva: Universidad de Granada, 2003) 
Peter Gay, The Cultivation of Hatred. The Bourgeois Experience. Victoria to Freud (London: Norton Company, 1993)

Peter N. Miller, Peiresc's Mediterranean World (Harvard University Press, 2015)

Richard L. Kagan, Los cronistas y la Corona. La política de la Historia en España en las Edades Moderna y Contemporánea (Madrid: Marcial Pons, 2009)

Vicente Risco, Historia de los judíos desde la destrucción del Templo (Barcelona: Ediciones Gloria, 1942)

Y. H. Yerushalmi, Zakhor. Histoire juive et mémoire juive (Paris: Gallimard, 1982)

Y. Yovel, The Other within. The marranos. Split Idendity and Emerging Modernity (Princeton University Press, 2009)

Yitzhak Baer, Historia de los judíos en la España cristiana (Barcelona: Riopiedras, 1982 [Tel Aviv, 1959])

Yom Tov Assis, The Golden Age of Aragonese Jewry. Community and Society in the Crown of Aragon, 1213-1327 (London: The Littman Library of Jewish Civilization, 1997)

\section{Profile}

José-Carlos Bermejo-Barrera is Professor of Ancient History in the University of Santiago de Compostela (Spain). He is author of several books on theory of history and history of religions, his most recent titles being Historia y melancolía (Madrid: Akal, 2018), La tentación del rey Midas. Para una economía política del conocimiento (Madrid: Siglo XXI, 2015) and Sueños para unas sombras. Caminos del mito griego (Santiago de Compostela: Enexebre Books, 2014).

José Carlos Bermejo-Barrera es catedrático de Historia Antigua en la Universidad de Santiago de Compostela (España). Es autor de numerosos libros de teoría de la historia e historia de las religiones. Sus trabajos más recientes son: Historia y melancolía (Madrid: Akal, 2018), La tentación del rey Midas. Para una economía política del conocimiento (Madrid: Siglo XXI, 2015) y Sueños para unas sombras. Caminos del mito griego (Santiago de Compostela: Enexebre Books, 2014). 
Fecha de recepción: 20 de febrero de 2019.

Fecha de aceptación: 27 de marzo de 2019.

Publicación: 30 de junio de 2019.

Para citar este artículo: José Carlos Bermejo Barrera, "Una escuela para el odio: los demonios familiares de la Historia de España”, Historiografías, 17 (enero-junio, 2019): pp. 51-65. 